\title{
Effects of Monomeric Sequence Distributions on Physical Properties of Thermotropic Liquid Crystalline Copoly(ester-imide)s
}

\author{
Tae Kyun KIm, Kwang Man KIM, and In Jae CHUNG ${ }^{\dagger}$ \\ Department of Chemical Engineering, Korea Advanced Institute of Science and Technology (KAIST), \\ 373-1 Kusong-dong, Yusong-ku, Taejon 305-701, Korea
}

(Received August 5, 1996)

\begin{abstract}
Thermotropic liquid crystalline copoly(ester-imide)s were synthesized from $n$-( $\omega$-carboxyalkylene) trimellitic imide, 2,6-dihydroxynaphthalene, and $p$-hydroxybenzoic acid. The synthesized polymers were abbreviated as PEIM, CPHA, CPHB, CPHC, and CPHD, corresponding to mole fractions of $p$-hydroxybenzoic acid (PHB) to PEIM varied from 0 to $1 / 3$, $1 / 2,2 / 3$, and $3 / 4$. We investigated the monomeric sequence distributions by high resolution ${ }^{13} \mathrm{C}$ NMR and their effects on the thermal, viscoelastic properties and molecular orientation of copoly(ester-imide)s. The solids of CPHA and CPHB with short runs of PHB blocks in a main chain preserved a nematic glassy state during the cooling process because of the slow crystallization. The low degree of crystallinity and slow crystallization rate were considered to be caused by the absence of long runs of PHB blocks. But CPHC with long runs of PHB blocks showed a high tendency to crystallize and, therefore, the hysteresis of viscoelastic properties in heating and cooling was observed. The residual crystallites of CPHC were considered to hinder the molecular orientation during melt spinning.

KEY WORDS Copoly(ester-imide)s / Monomeric Sequence Distributions / Crystallization / Viscoelastic Properties / Fiber / Molecular Orientation /
\end{abstract}

In recent years considerable interest has been developed in the rheological properties of thermotropic liquid crystalline polymers (TLCPs) because the rheological behavior is characterized by a number of unusual phenomena: long relaxation time, ${ }^{1,2}$ large supercooling behavior, ${ }^{3-6,12}$ and lower viscosity in the nematic phase than in the isotropic phase at a higher temperature. ${ }^{7-10}$

Temperature and time sweep measurements of rheological properties provide a useful insight into the natures of TLCPs in oscillatory shear flow. ${ }^{5,11-18}$ Many TLCPs showed a large difference in temperatures on heating and cooling at a fixed value of one property such as complex viscosity, which was called the hysteresis, due to the large supercooling behavior. Among them are $p$-hydroxybenzoic acid (PHB)/poly(ethylene terephthalate) (PET) and p-hydroxybenzoic acid (PHB)/ 2,6-hydroxynaphthoic acid (HNA) copolyesters included. ${ }^{4,10,12}$ This supercooling behavior indicates the quite different state on heating and cooling even at the same temperature. The dynamic modulus increased with time at a temperature below the nominal melting temperatures of TLCPs ${ }^{3,4,15,17}$ which was considered to be caused by the crystallization of the supercooled liquid crystalline polymers.

Many copolyesters have been reported to have the phase separation and the discontinuous morphology because they do not have a perfect randomness but blocked sequence distribution. ${ }^{19-21}$ Therefore, the molecular structures are considered important factors influencing the crystallization rate, crystallinity and the thermal history of viscoelastic properties.

The purpose of this work is to synthesize thermotropic liquid crystalline polymers with different molecular structures, investigate the monomer seuqences by using NMR with a high field and examine the relations between chemical structures and physical properties.

\section{EXPERIMENTAL}

\section{Materials}

Trimellitic anhydride was purchased from Aldrich Chemical Co. It was purified by recrystallization from hot acetic anahydride. 5-Aminovaleric acid and 2,6dihydroxynaphthalene (NAPH) and $p$-hydroxybenzoic acid (PHB) were purchased from Aldrich Chemical Co. and used without further purification. 2,6-Dihydroxynaphthalene and $p$-hydroxybenzoic acid were acetylated by means of boiling acetic anhydride. They were purified by washing repeatedly with methanol and dried under vacuum at $60^{\circ} \mathrm{C}$.

For the preparation of $n$-( $\omega$-carboxyalkylene) trimellitic imide, 5-aminovaleric acid $(0.2 \mathrm{~mol})$ and trimellitic anhydride $(0.2 \mathrm{~mol})$ were placed in $250 \mathrm{~mL}$ of dried dimethylformamide, and this mixture was refluxed at $120^{\circ} \mathrm{C}$ for $2 \mathrm{~h}$. Acetic anhydride $(0.4 \mathrm{~mol})$ was then added and refluxing was continued at $120^{\circ} \mathrm{C}$ for $2 \mathrm{~h} .{ }^{22}$ After it cooled, the reaction mixture was poured into an icecold water and the precipitated diacid was isolated by filtration. The products were recrystallized with a mixture of 1,4-dioxane and water, and dried at $80^{\circ} \mathrm{C}$ under vacuum.

\section{Polymerization}

$N$ - $(\omega$-Carboxyalkylene $)$ trimellitic imide $(30 \mathrm{mmol})$ and 2,6-diacetoxynaphthalene $(30 \mathrm{mmol})$ and various amounts of $p$-acetoxybenzoic acid with magnesium oxide $(30 \mathrm{mg})$ were heated in a round-bottomed cylindrical glass reactor equipped with a stainless steel stirrer. The reactants were condensed at $220-290^{\circ} \mathrm{C}$ for about $6 \mathrm{~h}$ under the nitrogen atmosphere, and then left in vacuum for $1 \mathrm{~h}$ at $270-290^{\circ} \mathrm{C}$ to eliminate acetic acid. The crude products after polymerization were cooled slowly under nitrogen condition and dissolved in a mixture

\footnotetext{
${ }^{\dagger}$ To whom all correspondence should be addressed. [Telephone: +82(42)869-3956, Facsimile: $\left.+82(42) 869-3910\right]$.
} 
of dichloromethane and trifluoroacetic acid $(4: 1$ by volume), and precipitated in methanol. The powder of polymers obtained were purified by washing with methanol and dried under vacuum at $80^{\circ} \mathrm{C}$. The chemical structures of polymers are shown in Scheme 1. For simplicity, the synthesized polymers were abbreviated as PEIM, CPHA, CPHB, CPHC, and CPHD, corresponding to mole fractions of PHB to PEIM varied from 0 to $1 / 3,1 / 2,2 / 3$, and $3 / 4$, respectively in Scheme 1. Homopolymer, PEIM, showed a stable nematic phase between $251^{\circ} \mathrm{C}$ and $343^{\circ} \mathrm{C}$. The detailed characteristics of homopolymer is not shown in this paper.
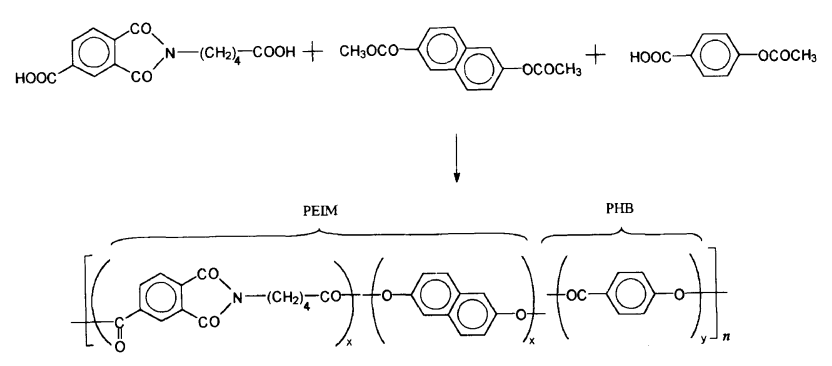

Scheme 1. Synthesis routes and chemical structures of copoly(esterimide)s.

\section{Measurements}

A polarized optical light microscope (PLM, A Leitz, Model Laborlux 12 Pols) coupled with a Mettler FP-2 hot stage was used to observe for the liquid crystalline textures of copoly(ester-imide)s.

Thermal analysis was carried out under nitrogen atmosphere with du Pont 910 analyzer. A typical sample weights were about $10 \mathrm{mg}$. The minimum position of a peak was taken as the transition temperature in DSC diagram.

Wide angle X-ray diffractograms (WAXD) were obtained by using Rigaku X-ray generator $\left(\mathrm{Cu}-K_{\alpha_{1}}\right.$ radiation with $\lambda=0.15406 \mathrm{~nm})$. A sample was prepared in the form of powder. The diffractograms were recorded in $2 \theta$ range between $2^{\circ}$ and $40^{\circ}$ at a rate of $4^{\circ} \mathrm{min}^{-1}$.

For the high field NMR spectra, clear solutions were prepared by dissolving $1-5 \mathrm{wt} \%$ of a polymer in deuterated trifluoroacetic acid. The ${ }^{13} \mathrm{C}$ NMR (Bruker, AMX FT $500 \mathrm{MHz}$ NMR spectrometer) spectra were obtained at $125 \mathrm{MHz}$. The proton-decoupled spectra were obtained using a rf pulse of $45^{\circ}$ combined with a relaxation delay of $20 \mathrm{~s}$ between pulses (the relaxation times for inversion-recovery experiments ranged from 2.5 to $3.1 \mathrm{~s}$ for the carbonyl carbons). ${ }^{19-21}$

For the measurements of viscoelastic properties, disks of approximately $2 \mathrm{~mm}$ thickness and $25 \mathrm{~mm}$ diameter were prepared by placing polymer powder and drying in a vacuum oven at $80^{\circ} \mathrm{C}$ for approximately $24 \mathrm{~h}$ to remove any residual solvent and moisture and molding the powder in a hot press at $280^{\circ} \mathrm{C}$ and $10 \mathrm{MPa}$ of pressure for $10 \mathrm{~min}$. The samples were allowed to cool slowly down to room temperature and were finally removed from the press about $3 \mathrm{~h}$ later and the molded disks were dried at $80^{\circ} \mathrm{C}$ for about $48 \mathrm{~h}$ in vacuum prior to measurement. Rheological measurements were performed with a rotational rheometer (Physica Rheo-Lab MC 120) with parallel plate of $50 \mathrm{~mm}$ diameter. The gap between plates was fixed at $0.5 \mathrm{~mm}$. A strain amplit- ude of $10 \%$ was employed. The rheological properties were not affected by the strain amplitude, $\gamma_{0}$ between $1 \%$ and $12 \%$ at an angular frequency $\omega=10 \mathrm{rad} \mathrm{s}^{-1}$ when the temperature was slightly above the solidification temperature. All experiments were carried out in nitrogen atmosphere in order to preclude oxidative degradation of the samples. Temperature control was satisfactory within $\pm 1^{\circ} \mathrm{C}$.

\section{RESULTS AND DISCUSSION}

\section{Structural Characteristic of Copoly(ester-imide)s}

The IR spectra of $n$-( $\omega$-carboxylalkylene $)$ trimellitic imide and copolymers in Figure 1 shows the characteristic absorbance wavenumber of the imide ring at 1778$1766 \mathrm{~cm}^{-1}$ (imide $\mathrm{I}, \mathrm{C}=\mathrm{O}$ symmetrical stretching), $1365-1342 \mathrm{~cm}^{-1}$ (imide II, imide ring axial vibration), $1115-1103 \mathrm{~cm}^{-1}$ (imide III, imide ring transverse vibration), and $730-727 \mathrm{~cm}^{-1}$ (imide IV, imide ring out-of-plane vibration). The absorbance band due to ester carbonyl $(\mathrm{C}=\mathrm{O})$ is completely obscured by the asymmetric stretching of imide carbonyl in the region around $1715 \mathrm{~cm}^{-1}$. These results indicate that the chemical imidization occurs successfully. The properties of copoly(ester-imide)s were given in Table I. In elementary analysis, the experimental results match very well with the calculated ones for the proposed structures of all copoly(ester-imide)s.

$125 \mathrm{MHz}{ }^{13} \mathrm{C}$ NMR spectra of a copoly(ester-imide) CPHA is shown in Figure 2. The calculated and observed ${ }^{13} \mathrm{C}$ chemical shift of aromatic rings in polymers are summarized in Table II. Two ${ }^{13} \mathrm{C}$ NMR peaks (atom no. 19 and 20) are observed a 178.4 and $167.7 \mathrm{ppm}$ for two carboxyl carbons of the $n$ - $(\omega$-carboxylalkylene $)$ trimellitic imide located between naphthalene units and only one peak (atom no. 1 and 8 ) at $171.5 \mathrm{ppm}$ for two carbonyl carbons of imide ring. The calculated and observed chemical shifts match each other very well. Also, we could observe ${ }^{13} \mathrm{C}$ NMR peaks of atoms (for example, atom no. 20 and 26) influenced by sequence distributions to be split and grow with PHB mol\% (see Figure 4).

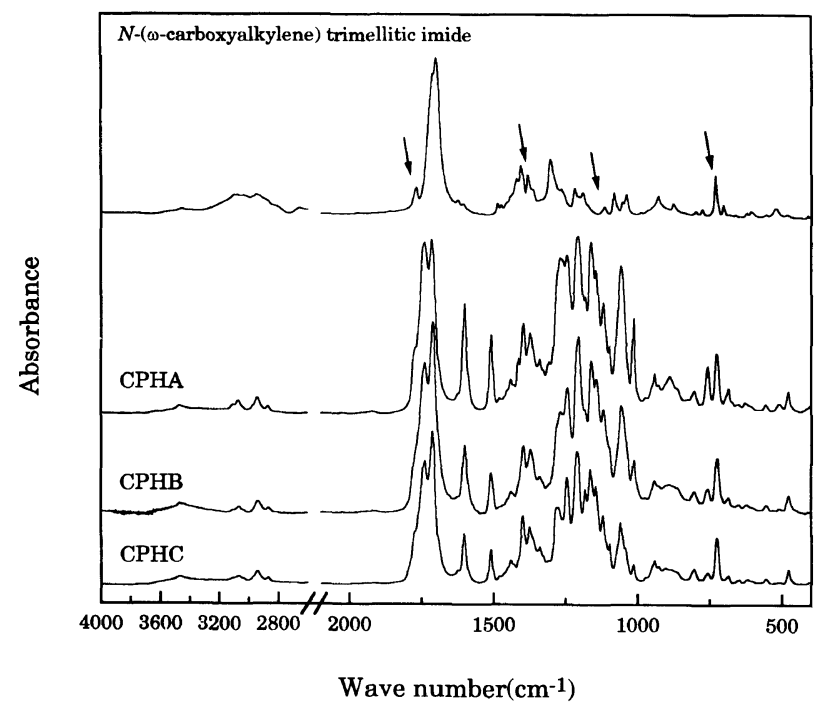

Figure 1. IR spectrum of $n$-( $\omega$-carboxyalkylene) trimellitic imide and copoly(ester-imide)s. 
Table I. Inherent viscosity, thermal properties, and elementary analysis of copoly(ester-imide)s

\begin{tabular}{|c|c|c|c|c|c|c|c|c|c|c|c|c|}
\hline \multirow{2}{*}{ Polymer } & \multirow{2}{*}{$\frac{\eta_{\text {ihn }}{ }^{\mathrm{a}}}{\mathrm{dL} \mathrm{g}^{-1}}$} & \multirow{2}{*}{$\frac{\text { Yield }}{\%}$} & \multirow{2}{*}{$\frac{T_{\mathrm{g}}^{\mathrm{b}}}{{ }^{\circ} \mathrm{C}}$} & \multirow{2}{*}{$\frac{T_{\mathrm{m}}{ }^{\mathrm{b}}}{{ }^{\circ} \mathrm{C}}$} & \multirow{2}{*}{$\frac{T_{\mathbf{i}}^{\mathrm{b}}}{{ }^{\circ} \mathrm{C}}$} & \multirow{2}{*}{$\frac{T_{\mathrm{s}}^{\mathrm{c}}}{{ }^{\circ} \mathrm{C}}$} & \multirow{2}{*}{$\begin{array}{c}\text { Formula } \\
\text { (formula weight) }\end{array}$} & \multicolumn{4}{|c|}{ Elementary analysis/\% } & \multirow{2}{*}{$\begin{array}{l}\text { Texture } \\
\text { by PLM }\end{array}$} \\
\hline & & & & & & & & 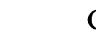 & & $\mathrm{H}$ & $\mathbf{N}$ & \\
\hline СРHB $(\mathrm{X}=1)$ & 0.52 & 89 & 94 & - & $\gg T_{\mathrm{d}}$ & 148 & $\begin{array}{c}\left(\mathrm{C}_{31} \mathrm{H}_{21} \mathrm{O}_{8} \mathrm{~N}\right)_{n} \\
535.5\end{array}$ & $\begin{array}{l}\text { Calcd } \\
\text { Found }\end{array}$ & $\begin{array}{l}69.53 \\
69.35\end{array}$ & $\begin{array}{l}3.95 \\
4.18\end{array}$ & $\begin{array}{l}2.62 \\
2.85\end{array}$ & Thread-like \\
\hline CPHC $(X=2)$ & 0.84 & 91 & 95 & 227 & $\gg T_{\mathrm{d}}$ & 188 & $\begin{array}{c}\left(\mathrm{C}_{38} \mathrm{H}_{25} \mathrm{O}_{10} \mathrm{~N}_{2}\right)_{n} \\
669.6\end{array}$ & $\begin{array}{l}\text { Calcd } \\
\text { Found }\end{array}$ & $\begin{array}{l}68.16 \\
69.95\end{array}$ & $\begin{array}{l}3.76 \\
3.96\end{array}$ & $\begin{array}{l}4.18 \\
4.21\end{array}$ & Thread-like \\
\hline CPHD $(\mathrm{X}=3)$ & insol. & 88 & 135 & 270 & $\gg T_{\mathrm{d}}$ & - & $\begin{array}{c}\left(\mathrm{C}_{25} \mathrm{H}_{19} \mathrm{O}_{6} \mathrm{~N}\right)_{n} \\
429.4\end{array}$ & $\begin{array}{l}\text { Calcd } \\
\text { Found }\end{array}$ & $\begin{array}{l}69.92 \\
69.85\end{array}$ & $\begin{array}{l}4.46 \\
4.37\end{array}$ & $\begin{array}{l}3.26 \\
3.14\end{array}$ & Thread-like \\
\hline
\end{tabular}

${ }^{\mathrm{a}} 0.2 \mathrm{~g} \mathrm{dL}^{-1}$ in dichloromethane/trifluoroacetic acid $\left(4: 1\right.$ by volume) at $20^{\circ} \mathrm{C}$. ${ }^{\mathrm{b}}$ From heating curve in DSC thermograms for annealed sample. ${ }^{\mathbf{c}}$ From viscoelastic properties. ${ }^{\mathrm{c}}$ Solidification temperatures from temperature sweep measurements for viscoelastic properties.

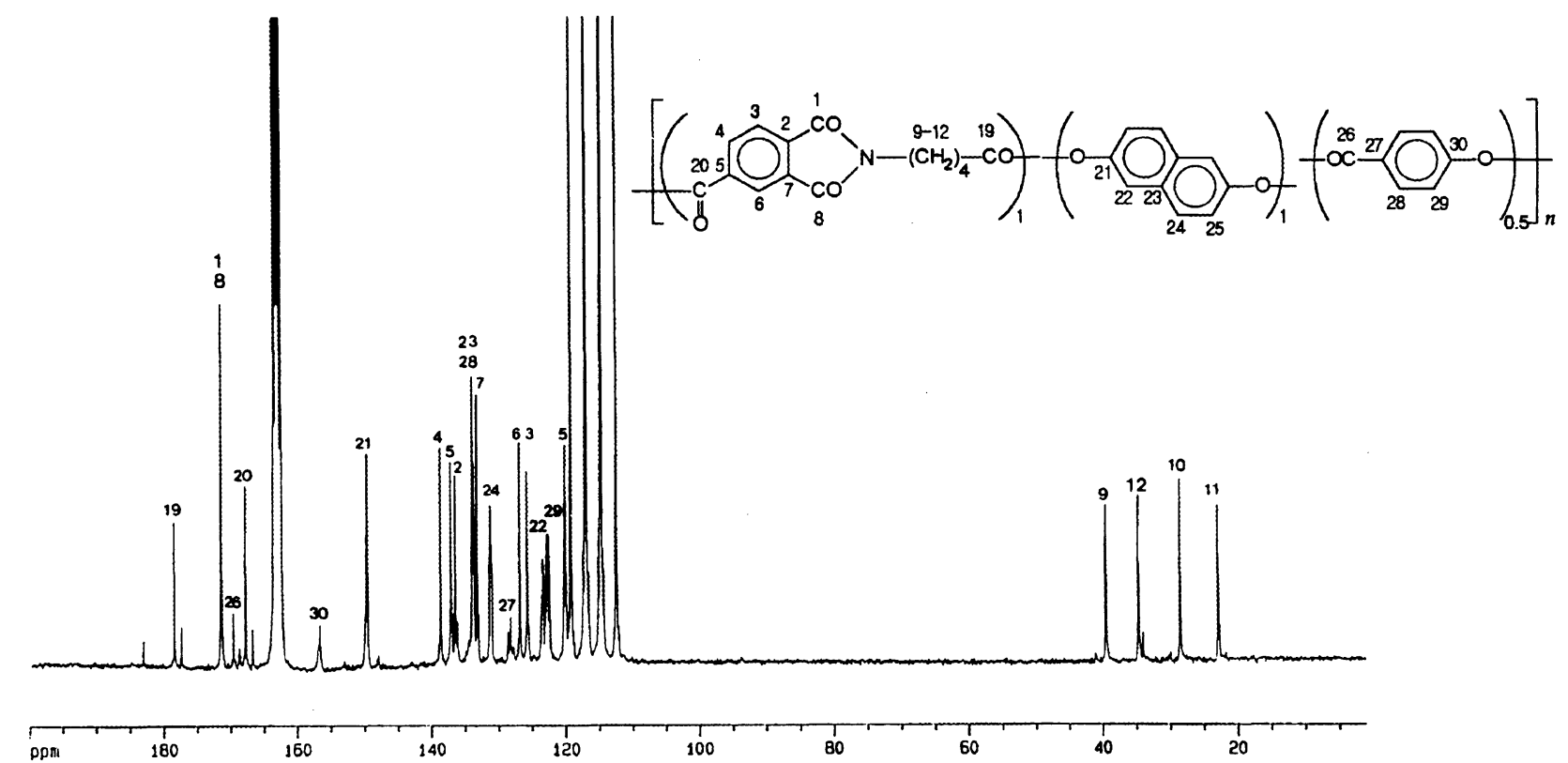

Figure 2. $125 \mathrm{MHz}{ }^{13} \mathrm{C}$ NMR spectra of CPHA with trifluoroacetic acid as a solvent.

Table II. Chemical shifts ( $\delta$ in ppm) and assignments of aromatic rings in polymers

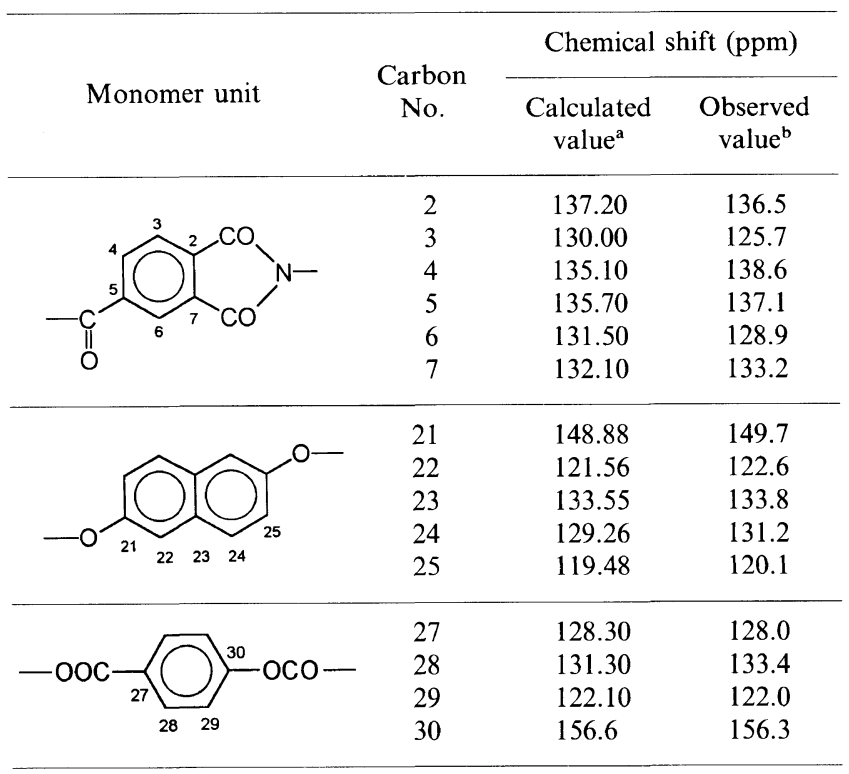

${ }^{a}$ Based on tabulated ${ }^{13} \mathrm{C}$ substituent effects on benzene and naphthalene (see ref 26). ${ }^{\mathrm{b}}$ Internal reference TFA $=112.31,114.97$, 117.22 , and $119.07 \mathrm{ppm}$.
Liquid Crystalline Phase of Copoly(ester-imide)s

For optical observations, a small amount of polymer was placed between glass plates and heated at the heating rate of $10^{\circ} \mathrm{C} \mathrm{min}^{-1}$. Figure $3(\mathrm{a})$, (c), and (e) shows the birefringence patterns of all copoly(ester-imide)s. They represent typical nematic textures with threadlike lines. When the temperature was close to isotropization temperature, $T_{\mathrm{i}}$ the optical texture changed from a threadlike to a circular shape as shown in Figures 3(b), (d), and (f). It seems that the isotropization transition and the thermal degradation take place simultaneously above $340^{\circ} \mathrm{C}$.

\section{NMR Sequence Distribution for Copoly(ester-imide)s}

Figure 4 illustrates the $125 \mathrm{MHz}{ }^{13} \mathrm{C}$ NMR spectrum of copoly(ester-imide)s in trifluoroacetic acid solution and shows assignments for resonances. The peaks of the carbonyl carbons of the PHB unit assigned to -PHB-PHB- and -PHB-NAPH- units grow with increment of PHB mol\%.

The NMR measurements provide the conditional probability of a PHB being bonded to a PHB or a NAPH unit. For the case of a random copolymer, the calculated probability of a PHB being bonded to a given PHB is 


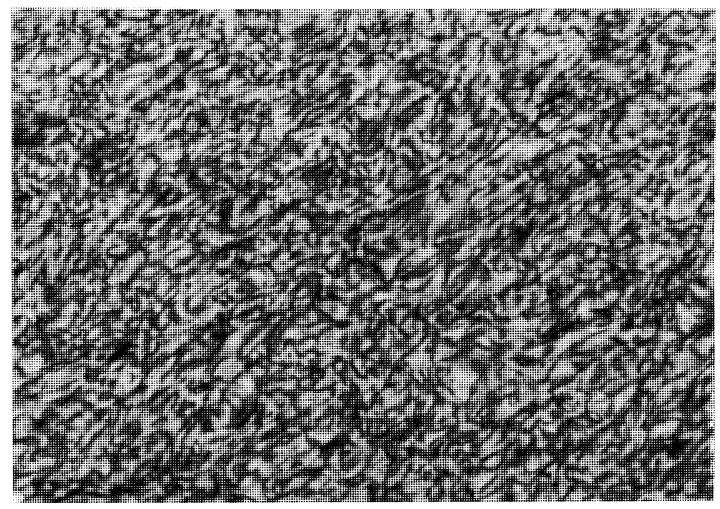

(a)

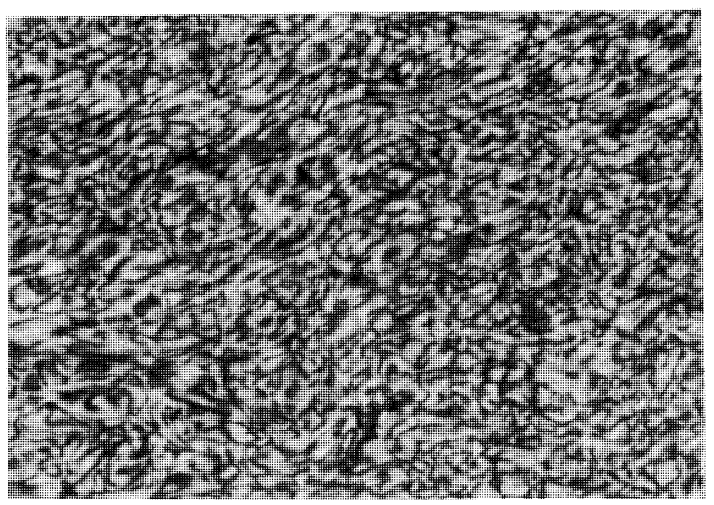

(c)

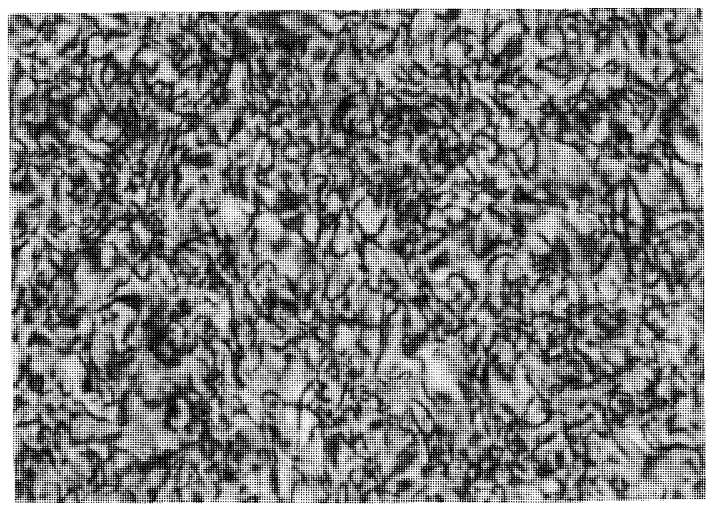

(e)

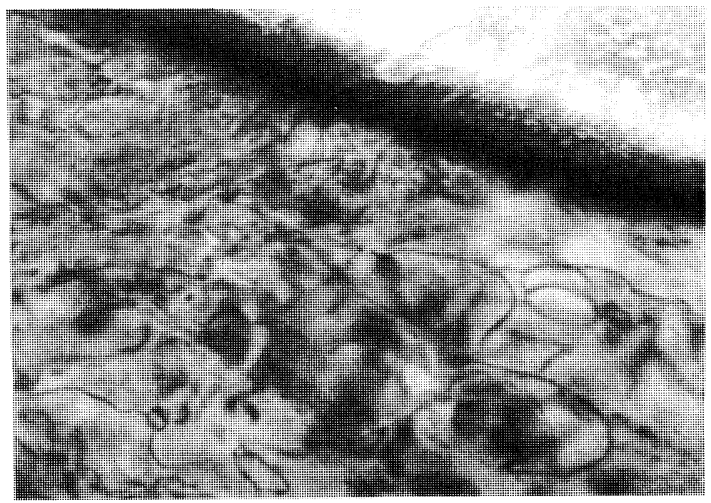

(b)

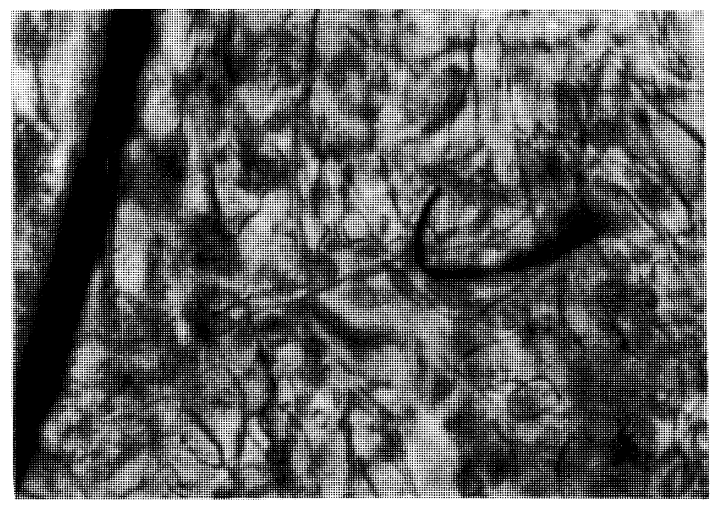

(d)

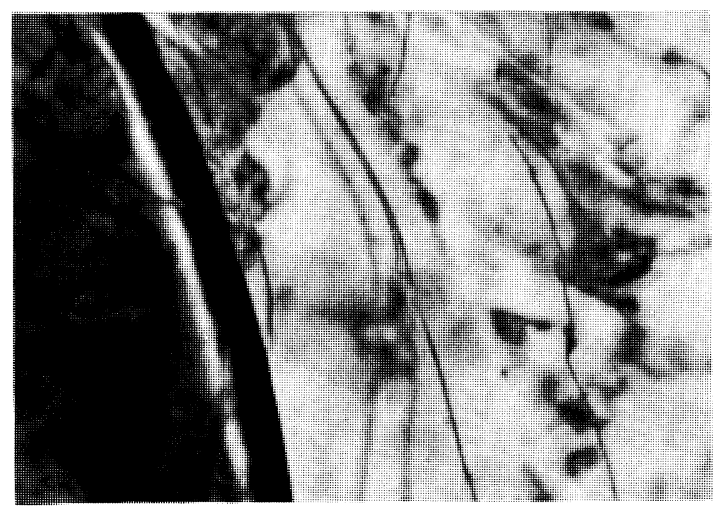

(f)

Figure 3. Liquid crystalline textures of all copoly(ester-imide)s under polarized optical microscopy $(\times 320)$ : (a) $T=280^{\circ} \mathrm{C}$ and (b) $T=350^{\circ} \mathrm{C}$ for CPHA; (c) $T=270^{\circ} \mathrm{C}$ and (d) $T=345^{\circ} \mathrm{C}$ for CPHB; (e) $T=280^{\circ} \mathrm{C}$ and (f) $T=350^{\circ} \mathrm{C}$ for CPHC.

given by

$$
\begin{aligned}
& P_{\mathrm{cal}}(\mathrm{PHB} / \mathrm{PHB}) \\
& \quad=P(\mathrm{PHB}) /[P(\mathrm{PHB})+2 \mathrm{P}(\mathrm{NAPH})]=a
\end{aligned}
$$

It is the theoreitcal probability based on a given composition. If $\mathrm{PHB}$ has a composition-independent preference for bonding to itself, the real probability from experiments is given by

$$
P_{\text {exp }}(\mathrm{PHB} / \mathrm{PHB})=m a
$$

where $m$ is the preference factor. Figure 5 shows the fraction of a PHB bonded to another PHB for several compositions of PHB in the copolymer. The solid and dotted lines indicate the calculated results for $m=1$ and $m=1.2$, respectively. A value of $m$ of 1.2 was chosen for the best fitting to experimental values and it indicates the possible deviations of the sequence distribution from randomness. The fact that only one single value for $m$ fits the experimental results supports the appropriateness of the model and the assumption on a single mechanism involved in the sequencing of repeat units.

Figure 6 shows the probability for sequence length distribution in three copoly(ester-imide)s. Mol\% of PHB for PHB-PHB consecutive bonding with sequence length $n$ can be calculated by $n(m a)^{n-1}(1-m a)^{2}$. The sequence distributions of CPHA and CPHB show small deviations from the random model with $m=1$ even though they 


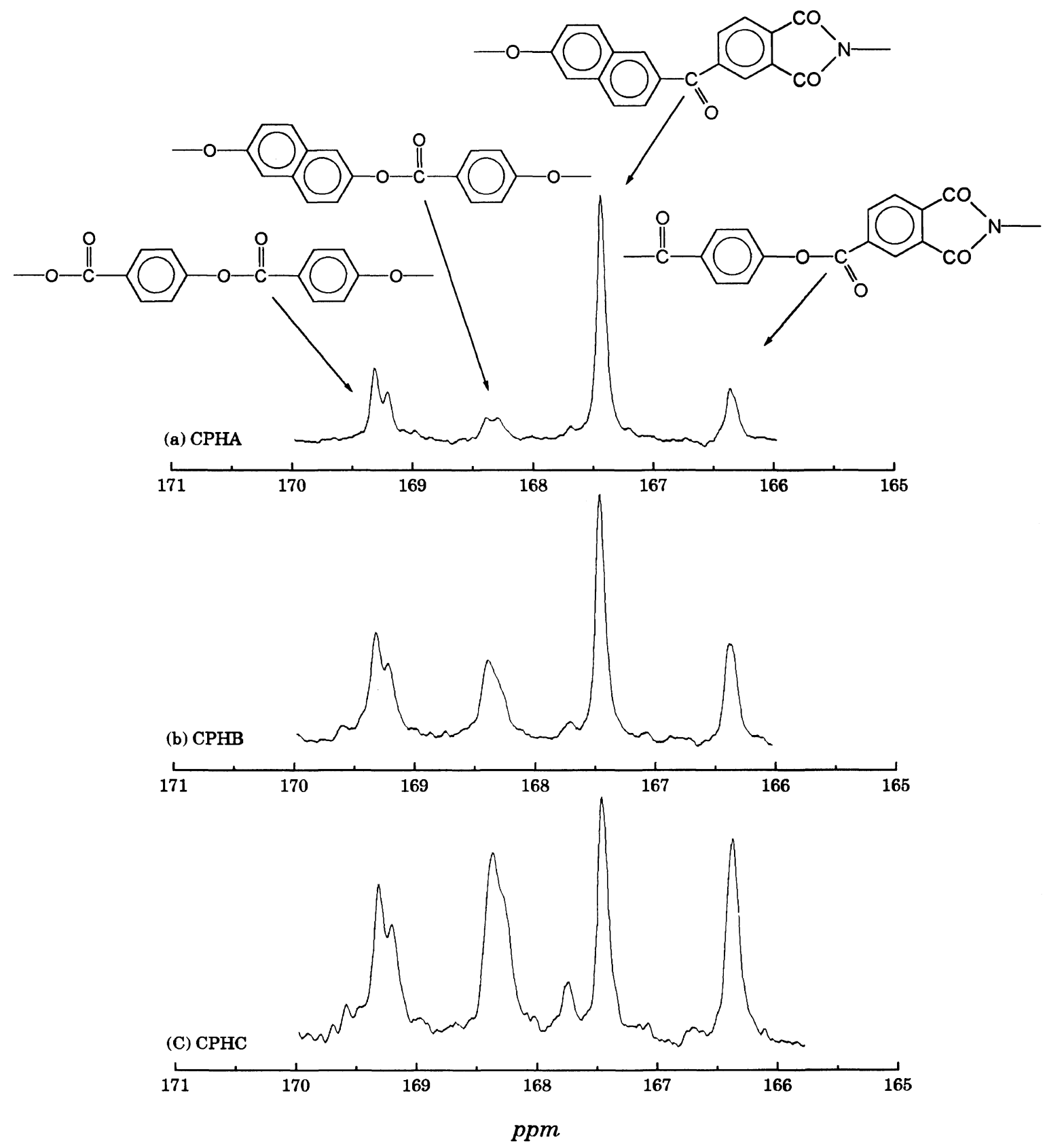

Figure 4. Portion of the ${ }^{13} \mathrm{C}$ NMR spectra at $125 \mathrm{MHz}$ for carbonyl carbons for copoly(ester-imide)s dissolved in trifluoroacetic acid.

have the preference of reaction, with the factor $m=1.2$. However, CPHC with the higher PHB composition shows a noticeable deviation from the random model and has a larger portion of long runs of PHB units than CPHA and CPHB. The NMR test was not carried out for CPHD because no suitable solvent could be found. However, if similar statistics apply, CPHD would have even more of long runs of PHB units.

\section{Thermal Properties of Copoly(ester-imide)s}

In Figure 7(a), CPHA dnd CPHB do not show exothermic transition on DSC traces even though annealing time, $t_{\mathrm{a}}$ is very long at various annealing temperatures, $T_{\mathrm{a}}$ but they have a glass transition only at three different temperatures. Generally, the solid state of TLCPs consists of the crystal and the nematic glassy state because crystallization and freezing of mesophase occur simultaneously in solidification. The absence of crystal- to-nematic transition indicates that $\mathrm{CPHA}$ and $\mathrm{CPHB}$ have a very low tendency to crystallize and keep the polymer nematic glassy state in nature during solidification. They show almost no deviation from the randomness in sequence distributions and have very short block of PHB units. The structural irregularity hinders the crystallization.

However, CPHC reveals the weak but reproducible crystal-to-nematic transition near $227^{\circ} \mathrm{C}$. Also, there is an exothermic transition corresponding to the nematicto-crystal transition on cooling. The crystal-to-nematic transition peak area grows with annealing time. Consequently, this result indicates that $\mathrm{CPHC}$ has the higher tendency to crystallize than CPHA and CPHB. The nematic-to-isotropic transition of all copoly(esterimide)s could not be observed because of the thermal degradation.

The X-ray diffractograms in Figure 8 provide us with 
similar information to those of DSC traces. WAXD pattern of CPHC becomes sharper with the annealing time but CPHA and CPHB show no change in patterns. This implies that the crystallinity of CPHC progressively increases with annealing time.

Several models have been proposed to describe the solid state structure of TLCPs. A most interesting model has been proposed by Windle et al., who suggest that short identical sequences in random copoly(HBA/HNA) chain match each other laterally, forming nonperiodic layer (NPL) crystals. $^{22,23}$ As mentioned before, CPHA and $\mathrm{CPHB}$ have little deviation from the randomness and very short sequence lengths. Therefore, they have a difficulty to match and pack the identical sequences in polymer chains and a low tendency of crystallization. On the other hand, CPHC has some deviation from the randomness and some long sequence lengths. It has more chances to form the blocked monomeric sequence and match the identical monomeric sequences laterally

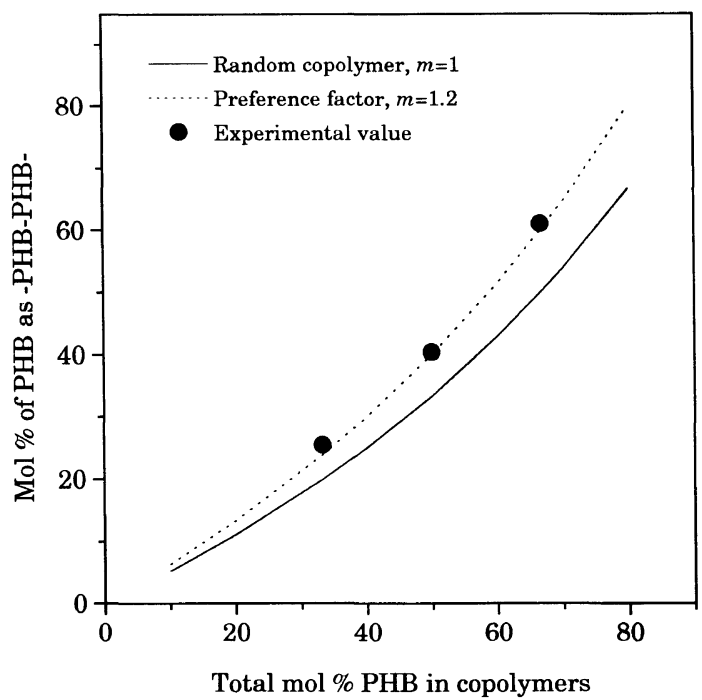

Figure 5. Mole percent of PHB connected directly to another PHB vs. total $\mathrm{mol} \%$ of PHB for copoly(ester-imide)s. Lines were calculated from a probability model described in the text. than CPHA and CPHB. Therefore, $\mathrm{CPHC}$ has a higher tendency to crystallize.

\section{Viscoelastic Properties of Copoly(ester-imide)s}

Figure 9 shows the temperature sweep measurements of storage modulus $G^{\prime}$, loss modulus $G^{\prime \prime}$, and the absolute value of complex viscosity $\left|\eta^{*}\right|$ for copoly(esterimide)s. After samples were first loaded at $280^{\circ} \mathrm{C}$ for $10 \mathrm{~min}$, they were cooled down slowly to a predetermined temperature and held for $10 \mathrm{~min}$ to equilibrate thermodynamically prior to measurements. The heating and subsequent cooling, or the cooling and subsequent heating was carried out between solidification temprature $\left(T_{\mathrm{s}}\right)$ and $280^{\circ} \mathrm{C}$ under nitrogen atmosphere. The heating and cooling rate was $2^{\circ} \mathrm{Cmin}^{-1}$, the frequency $10 \mathrm{rads}^{-1}$ and strain amplitude $10 \%$ for the dynamic test. The solidification temperature, $T_{\mathrm{s}}$ was taken as the temperature at which the crossover of $G^{\prime}$ and $G^{\prime \prime}$ curves occurs. $^{3}$

Figure 9(c) shows the hysteresis of CPHC on cooling and subsequent heating scan. On cooling, crystallization is delayed until a much lower temperature than the melting temperature and takes place suddenly below about $200^{\circ} \mathrm{C}$. On the subsequent heating the crystallization may continue until melting temperature $\left(T_{\mathrm{m}}=\right.$ $227^{\circ} \mathrm{C}$ ). The difference of melting and crystallization temperatures causes the hysteresis of the viscoelastic properties upon cooling and heating. This kind of thermal hysteresis has been found for many other TLCPs and can be explained by the supercooling effect on cooling and the existence of residual crystallites on heating. ${ }^{3-5,12}$

On the contrary, CPHA and CPHB do not show the thermal hysteresis over the whole nematic temperature range. On the DSC diagram, the crystallization is not observed. If the annealing period is very long enough, some crystallization may take place. It is reasonable to believe that large portion of nematic phase is kept and freezes to the namatic glassy state because of the very slow crystallization. Early, Wissbrun and Cogswell alluded to the possibility that the nematic phase could
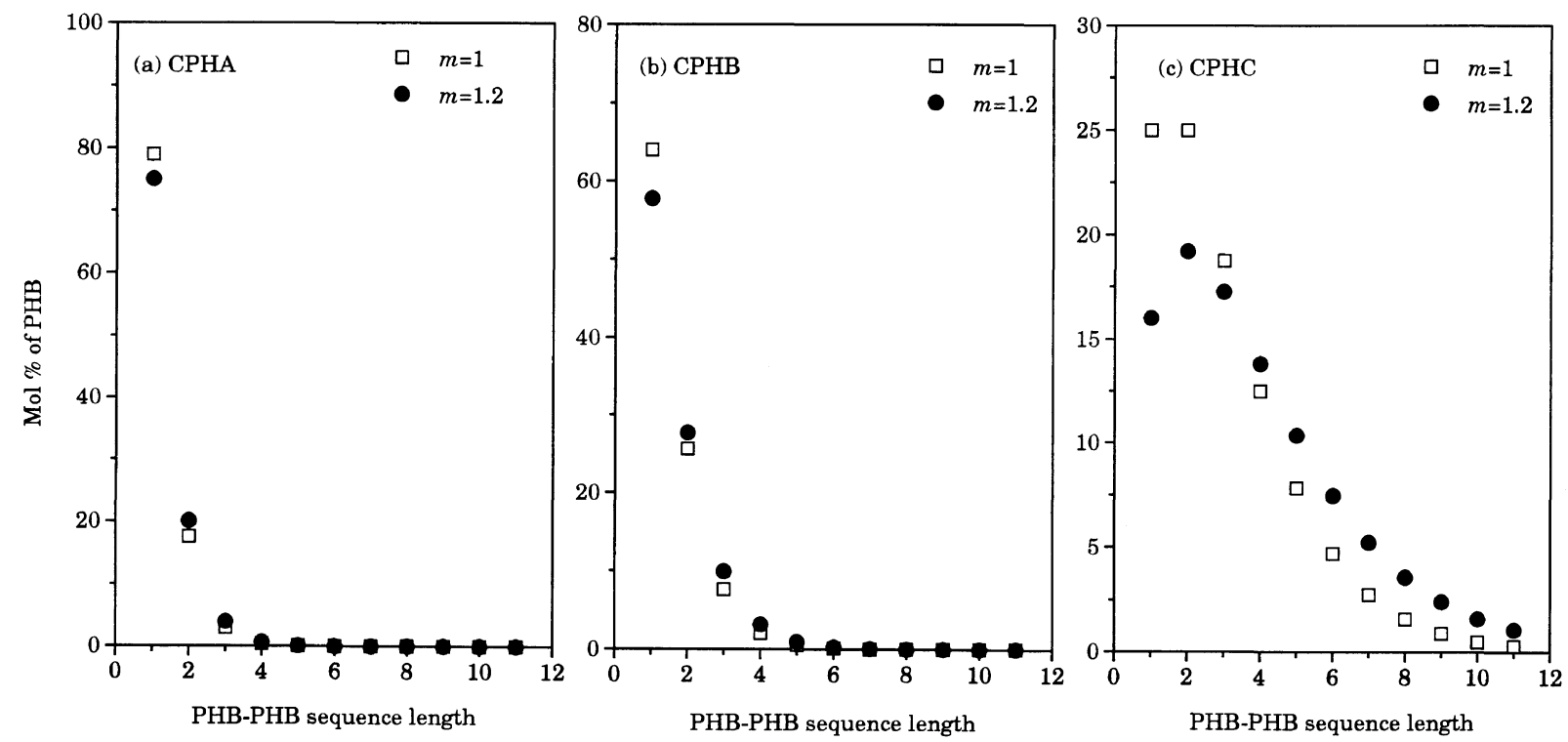

Figure 6. Mole percent of PHB units in (a) CPHA, (b) CPHB, and (c) CPHC in sequences of various lengths as calculated from the probability model of sequencing by using the data in Figure 5. 
be maintained at temperature below the melting temperature upon cooling because of the long relaxation time of TLCPs. ${ }^{1,2}$ Studies by Driscoll et al. provided the evidence that TLC poly[( $p$-fluorophenylene sulfonyls)$p$-phenylene-1,10-decamethylene-bis(4-oxybenzoate)] es-

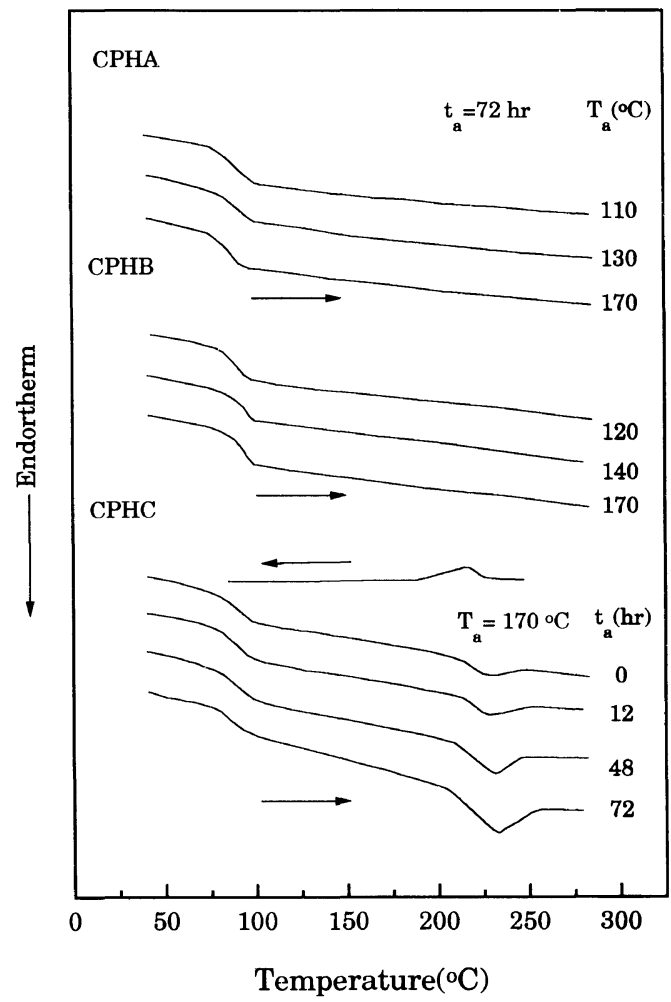

Figure 7. DSC thermograms for annealed copoly(ester-imide)s: heating at a rate of $10^{\circ} \mathrm{C} \mathrm{min}-1$ and cooling at a rate of $-1{ }^{\circ} \mathrm{Cmin}^{-1}$ : $T_{\mathrm{a}}$ and $t_{\mathrm{a}}$ are annealing temperature and time.

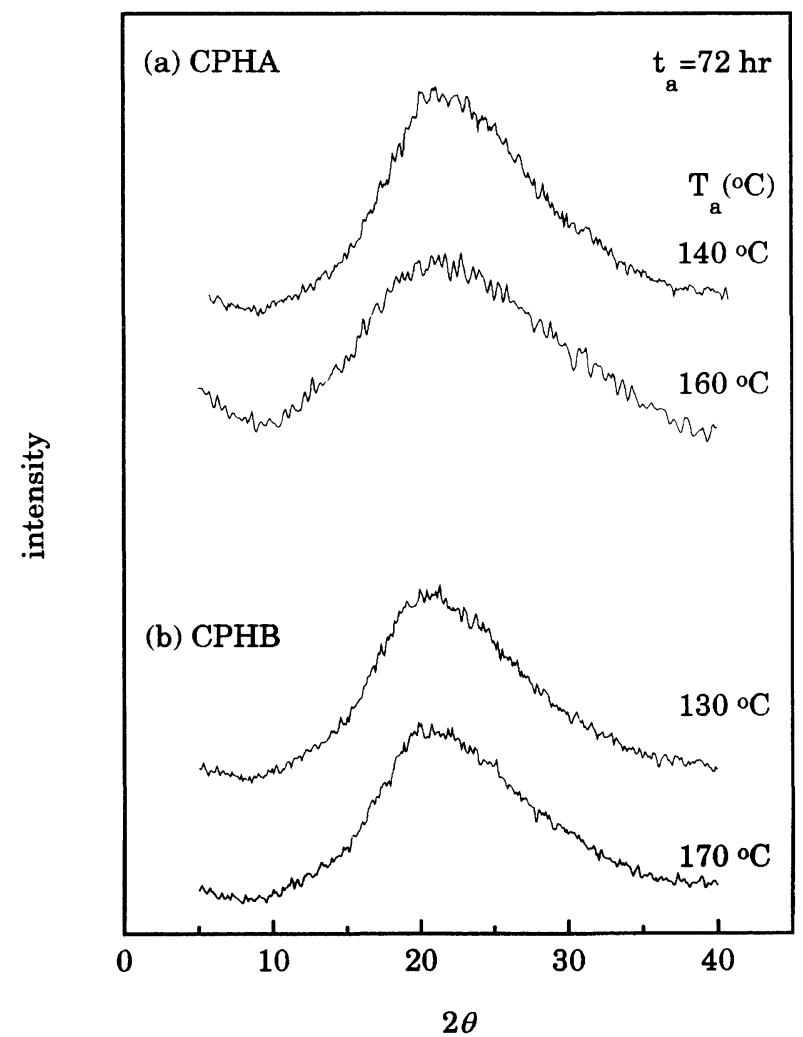

sentially show a little hysteresis in viscoelastic property on temperature sweep. ${ }^{10}$

To examine how fast the solidification occurs below the nominal melting temperature, time sweep experiments were carried out at various temperatures. A sample was preheated to $280^{\circ} \mathrm{C}$ for copoly(ester-imide)s, held for $10 \mathrm{~min}$, and rapidly cooled to a predetermined temperature for measrements. It took 60 to $150 \mathrm{~s}$ for the temperature to reach equilibrium. The time for the onset of solidification is determined by the crossover of $G^{\prime}$ and $G^{\prime \prime}$. The solidification is observed in the case of CPHC but not in the case of the other copolymers as shown in Figure 10. CPHC show the increase in dynamic moduli with time at 200 and $220^{\circ} \mathrm{C}$ below the melting temperature $\left(=227^{\circ} \mathrm{C}\right)$. It takes 3 and $7 \mathrm{~min}$ at 200 and $220^{\circ} \mathrm{C}$ for the storage modulus, $G^{\prime}$, to cross over $G^{\prime \prime}$, respectively. Similarly, Done et al. reported it took $6 \mathrm{~min}$ for $G^{\prime}$ of PHB80/PET20 copolymer to reach a constant growth rate at $270^{\circ} \mathrm{C}{ }^{4}$ These behaviors have been believed due to the crystallization of the supercooled melt of liquid crystalline polymers. ${ }^{3,4}$

For CPHA and CPHB, the dynamic moduli remain almost constant with time and the crossover of $G^{\prime}$ and $G^{\prime \prime}$ is not observed although the descending temperature profile suggests the solidification. The supercooled nematic phase is assumed to be preserved. It is seldom observed in other TLCPs. ${ }^{3,4}$

\section{Molecular Orientation and Mechanical Property of Copoly(ester-imide)s}

Melt spinning was carried out at a wall shear rate of $34.5 \mathrm{~s}^{-1}$ using a capillary with the length of $50 \mathrm{~mm}$ and $L / D$ ratio of 66.7 . A take-up machine was placed $60 \mathrm{~cm}$ below the spinneret.

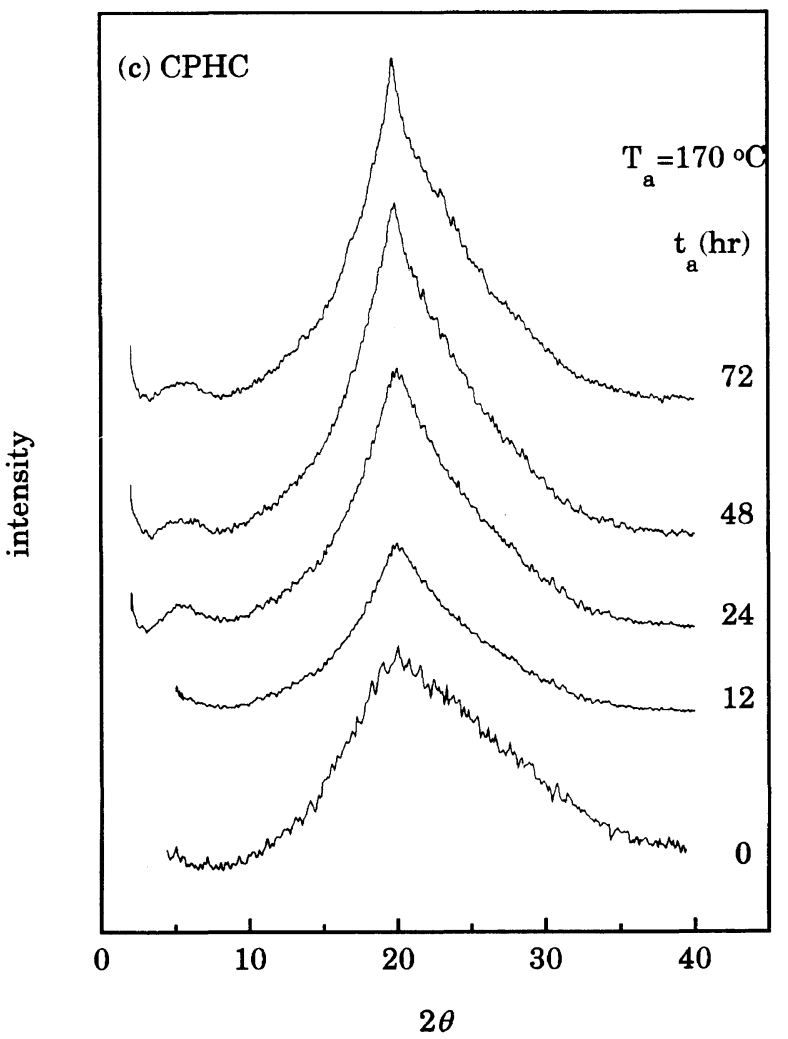

Figure 8. WAXD powder patterns for annealed copoly(eșter-imide)s. 


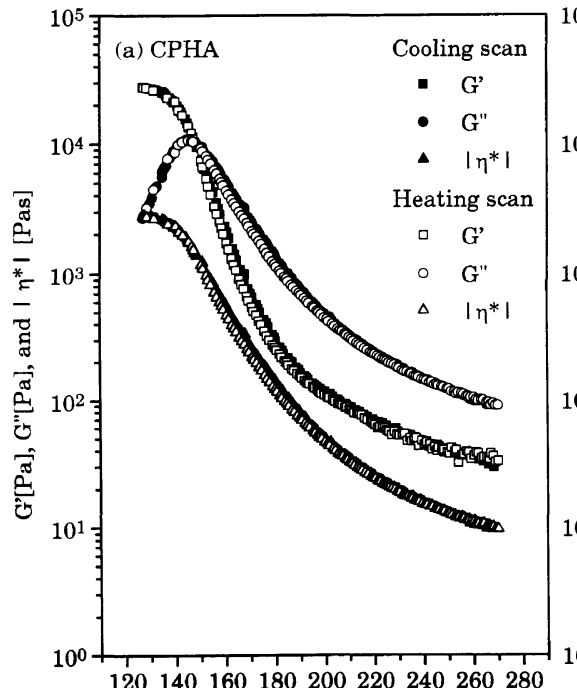

Temperature $\left({ }^{\circ} \mathrm{C}\right)$

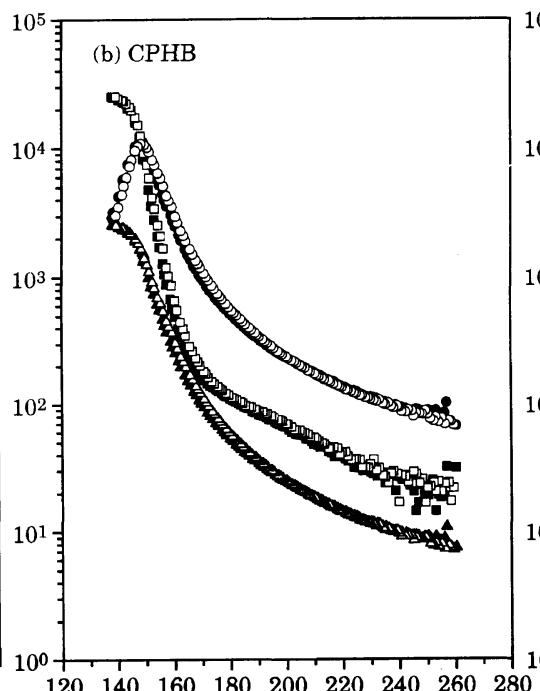

Temperature $\left({ }^{\circ} \mathrm{C}\right)$

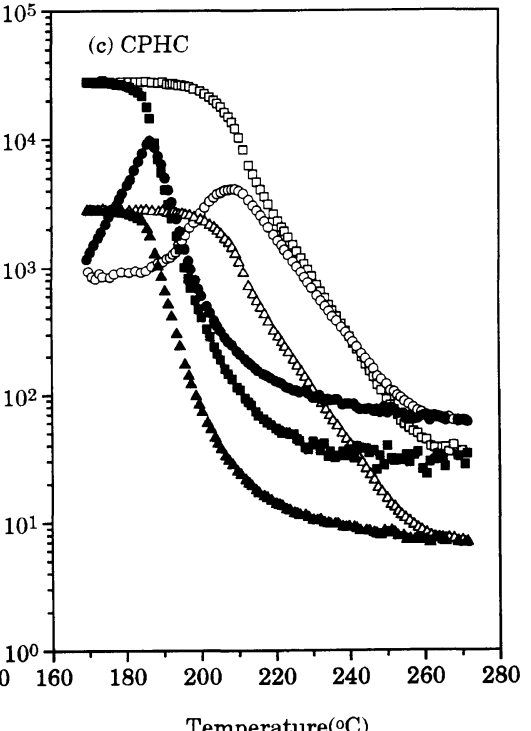

Temperature $\left({ }^{\circ} \mathrm{C}\right)$

Figure 9. Temperature sweep measurements of the viscoelastic properties for copoly(ester-imide)s at $\omega=10 \mathrm{rad} \mathrm{s}^{-1}$ and $\gamma_{0}=10 \%$ in a heating and cooling scan at a rate of $2^{\circ} \mathrm{Cmin}^{-1}$.
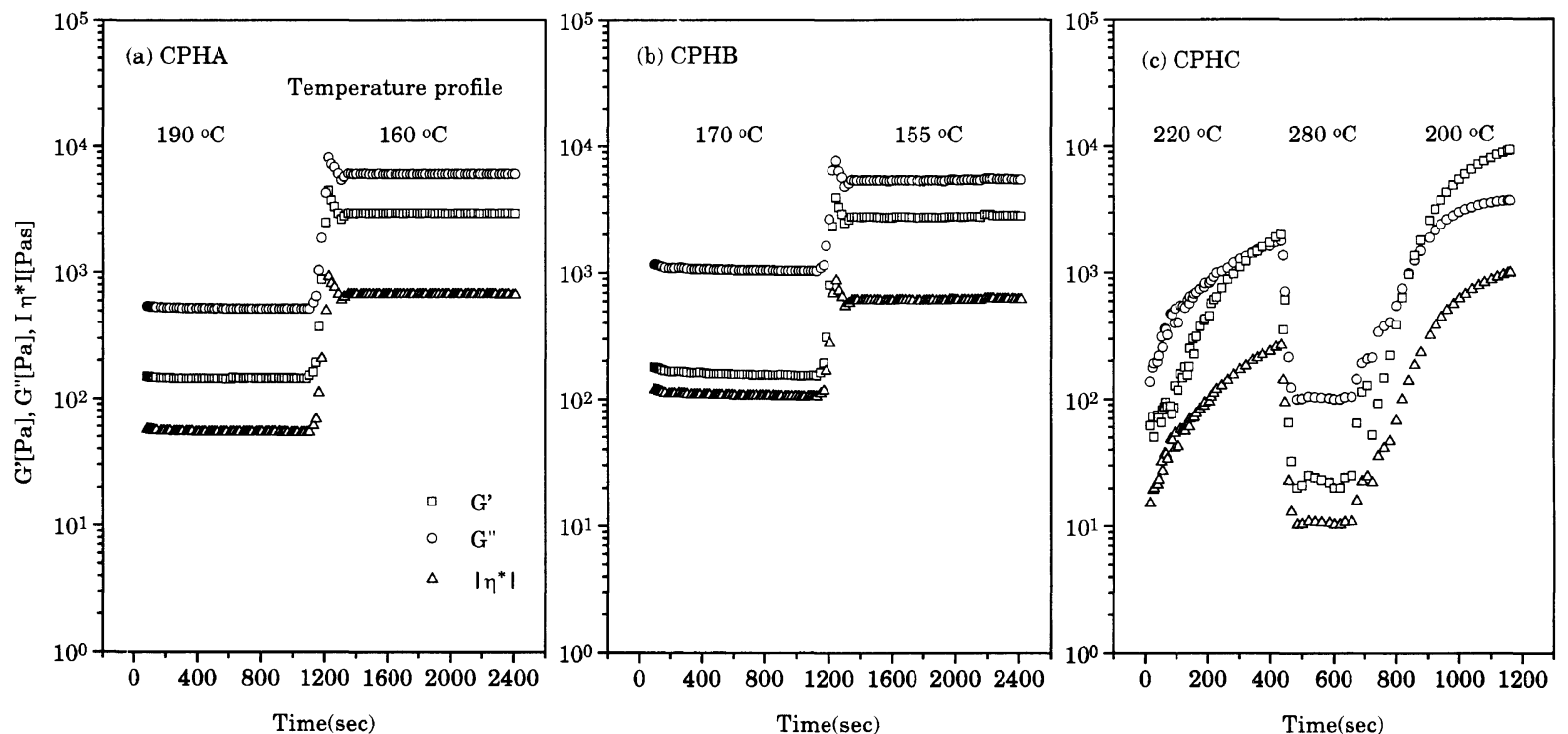

Figure 10. Time evolution of the viscoelastic properties below the nominal melting temperature of copoly(ester-imide)s at $\omega=10 \mathrm{rad} \mathrm{s}^{-1}$ and $\gamma_{0}=10 \%$.
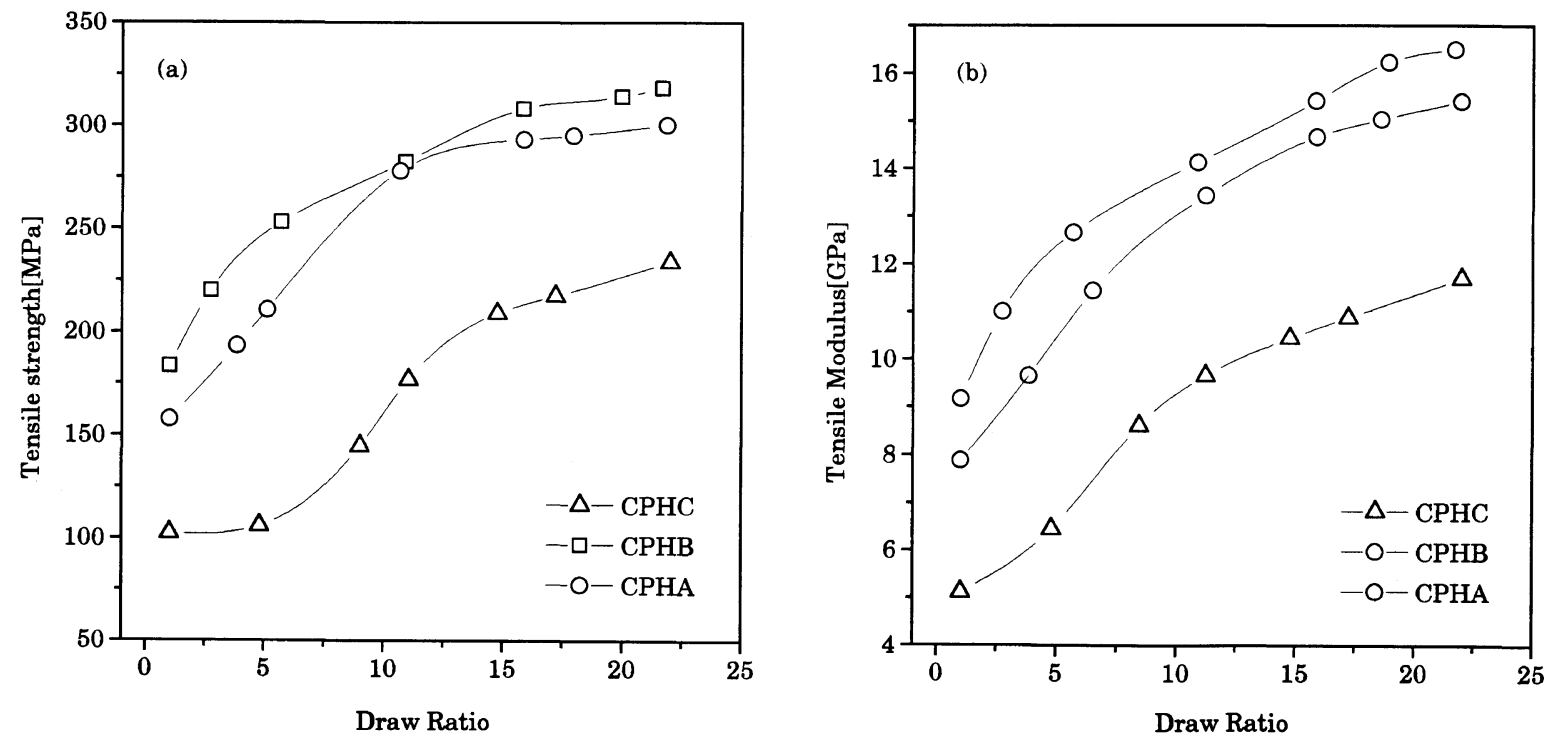

Figure 11. Mechanical properties of copoly(ester-imide) fibers as a function of draw ratio. 


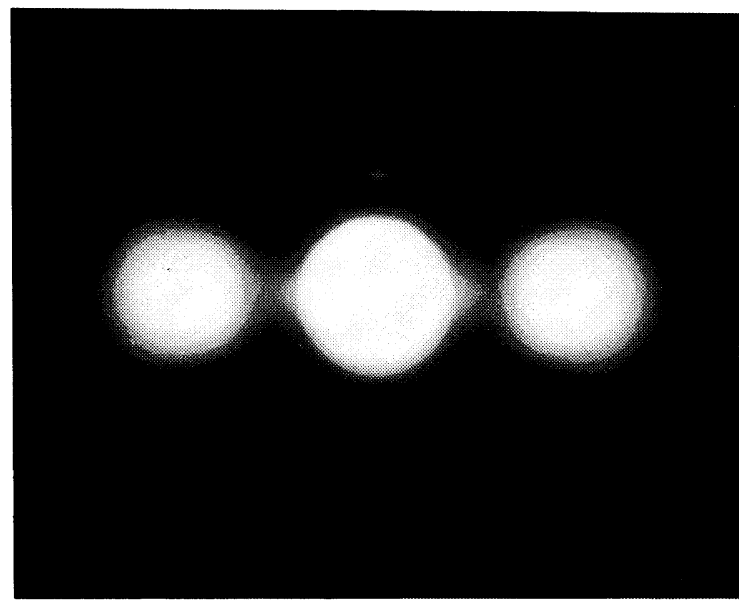

(a)

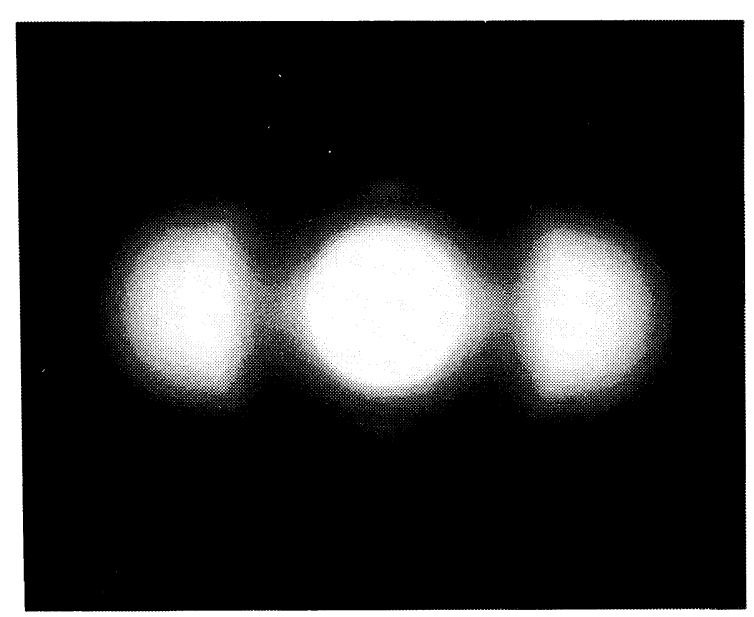

(c)

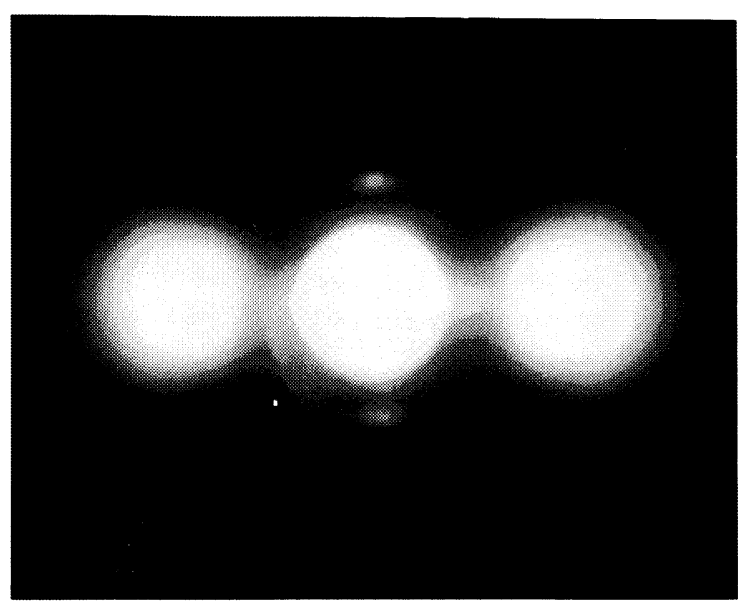

(b)

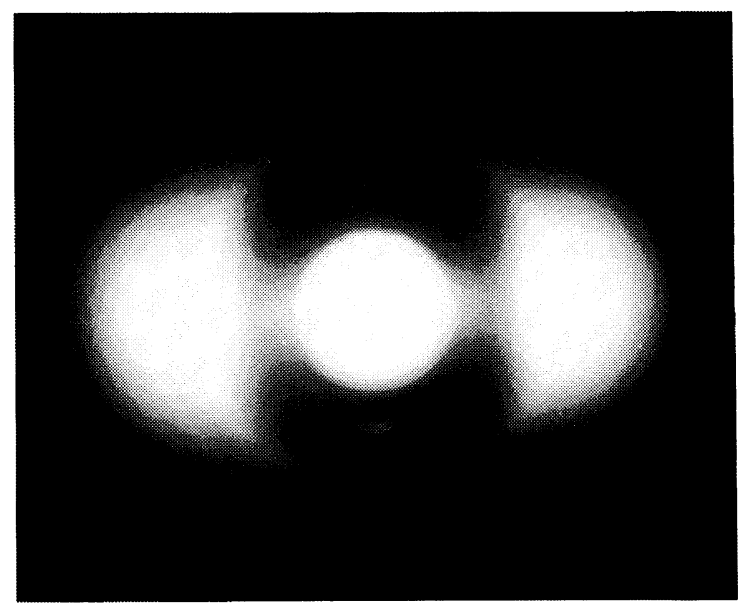

(d)

Figure 12. WAXD photographs for the fibers $(D R=10)$ : (a) $\mathrm{CPHA}$ with preheating to $260^{\circ} \mathrm{C}$, (b) $\mathrm{CPHA}$ without preheating, (c) $\mathrm{CPHC}$ with preheating to $260^{\circ} \mathrm{C}$, and (d) $\mathrm{CPHC}$ without preheating.

The fiber of a copoly(ester-imide) was spun at a temperature at which the complex viscosity of copolymers was about $300 \mathrm{~Pa} \mathrm{~s}^{-1}$ on heating in Figure 9. In Figure 11, tensile strength and modulus increase with the draw ratio for each sample. CPHC has the low tensile strength and modulus of fibers than CPHA and CPHB even though it has more PHB units with high rigidity. It may be explained by the existence of residual crystallites which hinder the molecular orientation in the fiber of CPHC during spinning.

Figure 12 shows WAXD patterns of fibers with draw ratio, $D R=10$. The azimuthal breath in the strongest equatorial reflection is small for the fiber of CPHA which indicates the high degree of orientation no matter whether the samples were preheated to $260^{\circ} \mathrm{C}$ or not prior to spinning. On the other hand, the molecular orientation is poor for the CPHC fiber without preheating to $260^{\circ} \mathrm{C}$ in Figure $12(\mathrm{~d})$. It was difficult for samples to be spun because of the fiber breakage. It is assumed that the poor molecular orientation and the difficult spinning are caused by the residual crystallites present during spinning. When the residual crystallites were melted by preheating $\mathrm{CPHC}$ to $260^{\circ} \mathrm{C}$ before spinning the fiber had a high molecular orientation as shown in Figure

Polym. J., Vol. 29, No. 1, 1997 12(c). ${ }^{11-14,27}$

\section{CONCLUSION}

It is observed from the analysis of carbon NMR spectra that CPHA and CPHB have a sequence distribution deviated a little from the randomness in sequence distributions and very short sequence lengths of PHB blocks, while CPHC with high PHB content deviates largely from the randomness and has long sequence lengths. The difference of sequence distributions results in the distinctive thermal behavior and viscoelastic properties of copoly(ester-imide)s. CPHA and CPHB show no crystallization in cooling even when annealed at temperatures above $T_{\mathrm{g}}$ for a long period. This result indicates that they preserve the nematic glass state after solidification. However, CPHC with long runs of PHB has a tendency to crystallize. It seems to have a higher probablity of matching of crystallizable sequence in the chain than the other copolymers. Its easy crystallization results in the hysteresis of viscoelastic properties and the growth of dynamic moduli. The fibers of CPHA and CPHB have a better molecular orientation and stronger tensile strength than those of CPHC. The existence of 
residual crystallites hinders the molecular orientation during the spinning and gives the weak tensile strength to the fiber of CPHC. It is recognized that a small modification in chemical structure affects greatly the physical properties of poly(ester-imide)s.

Acknowledgment. The authors thank Korea Science \& Engineering Foundation for the partial financial support through the grants-in-aid (KOSEF 94-0300-0401-3).

\section{REFERENCES}

1. K. F. Wissbrun, Br. Polym. J., 163 (1980)

2. F. N. Cogswell, Br. Polym. J., 170 (1980).

3. D. Done and D. G. Baird, Polym. Eng. Sci., 27, 816 (1987).

4. D. Done and D. G. Baird, Polym. Eng. Sci., 30, 989 (1990).

5. T. Masuda, K. Fujiwara, and M. Takahashi, Intl. Polym. Processing, 6, 225 (1991)

6. S. Kalika, M. R. Shen, X. M. Yu, M. M. Denn, P. Lanneli, N. Masciocchi, D. Y. Yoon, W. Parrish, C. Freiedrich, and C. Nöel, Macromolecules, 23, 5192 (1990).

7. K. F. Wissbrun and A. C. Griffin, J. Polym. Sci., Polym. Phys. Ed., 20, 1835 (1982).

8. A. Blumstein, O. Thomas, and S. Kumar, J. Polym. Sci., Polym. Phys. Ed., 24, 27 (1986).

9. S. S. Kim and C. D. Han, Macromolecules, 26, 3176 (1993).
10. P. Driscoll, K. I. Fujiwara, T. Masuda, A. Furukawa, and R. W. Lenz, Polym. J., 20, 351 (1988).

11. S. Hayase, P. Driscoll, and T. Masuda, Polym. Eng. Sci., 33108 (1993).

12. P. Driscoll, S. Hayase, and T. Masuda, Polym. Eng. Sci., 34, 519 (1994).

13. P. Driscoll, T. Masuda, A. Furukawa, R. W. Lenz, and S. Bhattacharya, Polym. J., 22, 609 (1990).

14. P. Driscoll, T. Masuda, and K. Fujiwara, Macromolecules, 24, 1567 (1991).

15. Y. G. Lin and H. H. Winter, Macromolecules, 21, 2439 (1988).

16. Y. G. Lin and H. H. Winter, Macromolecules, 24, 2877 (1991).

17. K. Huang, Y. G. Lin, and H. H. Winter, Polymer, 33, 4533 (1992).

18. D. S. Kalika, D. W. Giles, and M. M. Denn, J. Rheol., 34, 139 (1990).

19. A. Mühlebach, R. D. Johhson, J. Lerla, and J. Economy, Macromolecules, 21, 3115 (1988).

20. A. Zachariades, E. J. Economy, and J. A. Logan, J. Appl. Polym. Sci., 27, 2009 (1982).

21. E. Joseph, G. L. Wilks, and D. G. Baird, Polymer, 26, 689 (1985).

22. H. R. Kricheldorf and R. Pakull, and Buchner, J. Polym. Sci., Part A, Polym. Chem., 27, 431 (1989).

23. S. Hanria and A. H. Windle, Polymer, 29, 207 (1988).

24. S. Hanna, A. Romo-Uribe, and A. H. Windle, Nature, 366, 546 (1993).

25. A. Biswas and J. Blackwell, Macromolecules, 21, 3146 (1988).

26. G. C. Levy, R. L. Lichter, and G. L. Nelson, "Carbon-13 Nuclear Magnetic Resonance Spectroscopy," Wiley-Interscience, New York, N.Y., 1980.

27. S. K. Kwon and I. J. Chung, Eur. Polym. J., 30, 1081 (1994). 